\title{
Effects of recurrent sevoflurane anesthesia on cognitive functions with streptozotocin induced Alzheimer disease
}

\author{
Erkent $\mathrm{FD}^{1}$, Isik B ${ }^{2}$, Kucuk $\mathrm{A}^{3}$, Ozturk L ${ }^{4}$, Neselioglu $\mathrm{S}^{5}$, Dogan $\mathrm{HT}^{6}$, Guney $\mathrm{S}^{7}$, Arslan $\mathrm{M}^{2}$ \\ Hitit University School of Medicine, Department of Anesthesiology and Reanimation, Corum, Turkey. \\ mustarslan@gmail.com
}

\section{ABSTRACT}

OBJECTIVE: We aimed to investigate the effects of recurrent sevoflurane anesthesia on cognitive functions in Alzheimer Disease.

MATERIALS AND METHODS: Rats were divided into 4 groups as followed: control (Group C), sevoflurane (Group S), Alzheimer's (Group A) and Alzheimer's + sevoflurane (Group AS)]. Cognitive functions were evaluated with Radial Arm Maze Test (RAMT). Alzheimer model was created by administering $3 \mathrm{mg} / \mathrm{kg}$ (10 $\mu l)$ STZ. Sevoflurane was administered to $S$ and AS groups. Serum samples and hippocampus tissues were analyzed.

RESULTS: In RAM test, the entry-exit data were significantly decreased in A and AS groups. After the 2nd and 3rd administration of anesthesia, the numbers were significantly decreased in Group S. Glial-fibrillaryacidic protein levels were significantly higher in AS compared to the $\mathrm{C}$ and $\mathrm{S}$ groups. The brain tissue caspase 3 activity was less than 1\% in all rats in the Group C, $3 \%$ in 2 rats and $1 \%$ in 1 rat in the Group AS. In A and AS group, serum catalase, myeloperoxidase and ferroxidase activities were found to be higher than in the other groups and myeloperoxidase activity was higher in the AS than in the A Group. Serum native thiol, total thiol and disulfide levels were found to be significantly different in the A and AS groups. CONCLUSION: Sevoflurane anesthesia negatively affected the cognitive functions (Tab. 5, Fig. 10, Ref. 51). Text in PDF www.elis.sk.

KEY WORDS: Alzheimer, sevoflurane, Radial Arm Maze Test, rat, GFAP, Caspase-3.

\section{Introduction}

Worldwide, 200 million patients undergo anesthesia for surgical intervention each year. As overall life expectancy has increased, an increasing number of elderly patients receive anesthesia (1). Although the relevance of anesthesia and Alzheimer Disease (AD) findings to old human has been questioned on theoretical grounds. It is very important to decide how to manage anesthesia in elderly patients or patients with Alzheimer disease.

Alzheimer's disease (AD), which was described by Alois Alzheimer in 1907, is the most common form of progressive, irreversible dementia in the elderly. It affects more than 25 million people worldwide; without a major therapeutic breakthrough, its

${ }^{1}$ Hitit University School of Medicine, Department of Anesthesiology and Reanimation, Corum, Turkey, ${ }^{2}$ Gazi University School of Medicine, Department of Anesthesiology and Reanimation, Ankara, Turkey, ${ }^{3}$ Kütahya Health Science University School of Medicine, Department of Physiology, Kütahya, Turkey, ${ }^{4}$ Yildirim Bayazit University School of Medicine, Department of Anesthesiology and Reanimation, Ankara, Turkey, ${ }^{5}$ Yildirim Bayazit University School of Medicine, Department of Medical Biochemistry, Ankara, Turkey, ${ }^{6}$ Yildirim BayazitUniversity School of Medicine, Department of Medical Pathology, Ankara, Turkey, and ${ }^{7}$ Gazi University School of Medicine, Department of Physiology, Ankara, Turkey

Address for correspondence: M. Arslan, Dr, Gazi University School of Medicine, Department of Anesthesiology and Reanimation, 06510 Ankara, Turkey.

Phone: +90.312.2026739, Fax: +90.312.2024166 prevalence is expected to increase more than 100 million by 2050 (1). The diagnosis of AD is based on a positive history, neurological examination, and neuropsychological tests. However, the definitive diagnosis of $\mathrm{AD}$ is made by postmortem histopathologic evaluation. The two histopathological hallmarks of $\mathrm{AD}$ are senile plaques composed of extracellular aggregates of the beta-amyloid peptide and intraneuronal neurofibrillary tangles, composed of abnormally hyperphosphorylated tau protein assembled into paired helical filaments (2). Predisposing factors for AD are not yet fully understood. It is thought to be affected by many environmental factors as well as genetic transition $(3,4)$.

The role of anesthesia in the development of postoperative cognitive dysfunction is still unclear. Recent studies showed, that volatile anesthetics may impair cognitive functions of older patients (5-9). They also showed that there might be a relationship between drugs used in general anesthesia and Alzheimer's disease progress. Although we do not use ether anesthesia in our current anesthesia practice, Ikeada et al demonstrated that ether anesthesia increases tau phosphorylation in rat hippocampus (10). It has been shown that volatile anesthetics can induce synaptic dysfunction and neuronal apoptosis and thus lead to cognitive disorders in elderly brains. It is thought that intracellular $\beta$-amyloid levels increase the synthesis of $\beta$-amyloid and tau protein and disrupt the intracellular calcium metabolism (1). In many researches, isoflurane has been shown to increase caspase activity and increase amyloid $\beta$ in vivo $(11,12)$. There is also some research suggesting that sevoflurane 


\section{7-893}

and desflurane can lead to postoperative cognitive dysfunction and may progress to $\operatorname{AD}(13,14)$.

In this experimental research; the radial arm maze test (RAMT) was used to evaluate the cognitive function in rats (18). Oxidative stress was evaluated with catalase, myeloperoxidase, ferroxidase activities, myeloperoxidase, nativethiol, brain tissue caspase activity and GFAP.

In this study, we aimed to determine whether there is any change in cognitive function after a repeated sevoflurane anesthesia in elderly rats with streptozotocin-induced Alzheimer's diseases and we also demonstrated a immunohistochemical and pathological evidence of this change.

\section{Materials and methods}

\section{Animal models and experimental protocol}

This study was carried out in the GUDAM Laboratory of Gazi University with the approval of the Experimental Animals Ethics Committee of Gazi University (GÜET-17.081). All procedures were carried out in accordance with the standards in the Guide for the Care and Use of Laboratory Animals. In this study, 24 elderly Wistar Albino rats weighing between 250 and $300 \mathrm{~g}$, raised under the same environmental conditions, were used. The 24 rats were randomly separated into four groups. Control group ( $\mathrm{n}=6$, Group C), sevoflurane ( $\mathrm{n}=6$, Group S), Alzheimer's ( $\mathrm{n}$ $=6$, Group A) and Alzheimer's + sevoflurane ( $\mathrm{n}=6$, Group AS). $100 \mathrm{mg} / \mathrm{kg}$ ketamine (Ketalar; Parke-Davis; Pfizer, Inc, New York, NY, USA) was applied intraperitoneally to all rats in the group A and AS and stereotactic head was positioned. It was entered under the dura with burr hole from the mid-line. As in previous research, experimental Alzheimer's disease was created by giving $3 \mathrm{mg} / \mathrm{kg}$ $(10 \mu \mathrm{l})$ streptozotocin (Sigma Chemical, St. Louis, MO, USA), to Group A and AS intracerebroventricularly (15-17) (Fig. 1). Radial

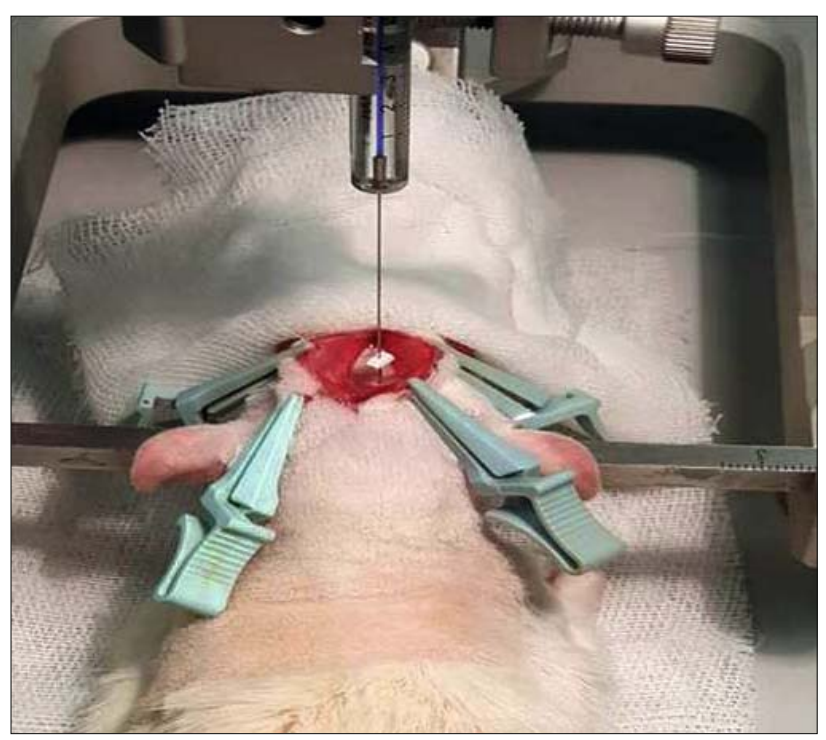

Fig. 1. Formation of Alzheimer's with injection of intracerebroventricular streptozotocin to rats by stereotaxic instrument.

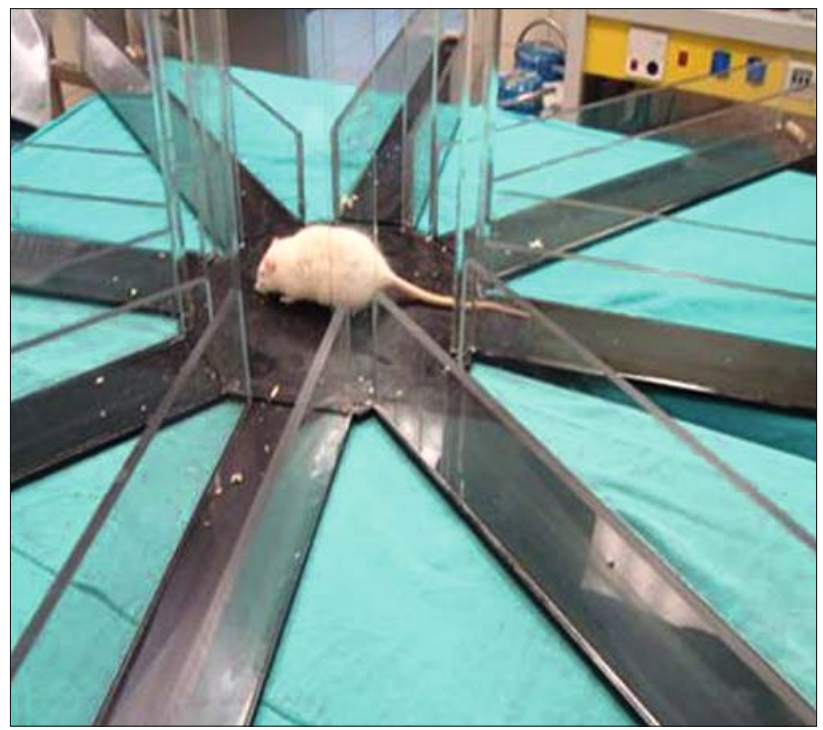

Fig. 2. The application of Radial Arm Maze Test (RAMT) in rats.

Arm Maze Test was applied to all the groups. The original design of Radial Arm Maze consisted of a $34 \mathrm{~cm}$ wide central platform with eight equal-length arms radiating out. Each arm had food sites at the end that were not visible from the central area; four arms had food at the distal end, and the other four arms did not have any. During a trial of the RAMT, an animal must acquire food from all the four areas of the maze $(18,19)$. Animals were placed individually in the center of the maze. In the RAM test, the number of input-output of the rats in the arms was studied. Four weeks after surgery, Group S and Group AS were administered sevoflurane 2.3 $\%$ for 3 consecutive days for 2 hours. Following each anesthesia in Group S and AS, RAMT was administered (simultaneously in Group C and A), and data were recorded (Fig. 2). After 24 hours from this administration, all the rats were euthanized under a ketamine anesthesia and their blood was taken. Serum samples were biochemically evaluated and hippocampus tissues were evaluated using histopathologic techniques.

\section{Histochemical and immunohistochemical evaluation}

Coronal cut sections were performed on formaline fixed brain tissues of the rats. Thus, slices containing hippocampus were obtained. After tissue processing, embedding in paraffin and sectioning immunohistochemistry for caspase 3 and GFAP was performed on 3 micrometer cut sections of the 16 samples using automated Leica Bond-max system. After de-paraffinization and dehydration Bond Epitope Retrieval solution (Leica Microsystems) was used for antigen unmasking for each antibody. After peroxide block placement the slides were incubated with antibodies against caspase 3 (Santa Cruz Biotechnology, P11, 1:200) and GFAP (GA-5, NeoMarkers, 1:300) for 15 minutes. The incubation with Post Primary reagent (Leica microsystems) was followed by washing with Bond Wash solution. Bond Polymer placement was followed by DAB (3,30diaminobenzidinetetrahydrochloride) as a chromogen for 6 minutes, hematoxylin counterstaining and mounting of the slides. 
Tab. 1. Input-output RAM data of rats (Mean \pm SD).

\begin{tabular}{|c|c|c|c|c|c|}
\hline Rat & $\begin{array}{c}\text { Group C } \\
(n=6)\end{array}$ & $\begin{array}{c}\text { Group S } \\
(n=6)\end{array}$ & $\begin{array}{c}\text { Group A } \\
(n=6)\end{array}$ & $\begin{array}{c}\text { Group AS } \\
(n=6)\end{array}$ & $\mathrm{p}^{* *}$ \\
\hline First & $6.60 \pm 1.03$ & $6.50 \pm 0.96$ & $5.30 \pm 0.48$ & $5.60 \pm 0.51$ & 0.579 \\
\hline 1th week & $4.40 \pm 0.89$ & $5.00 \pm 1.08$ & $3.00 \pm 0.71$ & $4.00 \pm 0.45$ & 0.368 \\
\hline 2 th week & $5.40 \pm 0.87$ & $4.50 \pm 0.29$ & $1.50 \pm 0.29 *,+$ & $2.60 \pm 0.40^{*},+$ & $<0.0001$ \\
\hline 3th week & $4.60 \pm 0.40$ & $4.75 \pm 0.25$ & $2.00 \pm 0.91 *,+$ & $2.00 \pm 0.55^{*},+$ & 0.011 \\
\hline 4th week & $4.40 \pm 1.07$ & $4.00 \pm 0.41$ & $1.50 \pm 0.50 *,+$ & $1.40 \pm 0.40 *,+$ & 0.010 \\
\hline After the first anesthesia & $3.60 \pm 0.75$ & $2.25 \pm 0.48$ & $1.75 \pm 0.63 *$ & $1.20 \pm 0.20 *$ & 0.037 \\
\hline After the third anesthesia & $3.60 \pm 0.75$ & $1.50 \pm 0.50 *$ & $1.25 \pm 0.48^{*}$ & $0.80 \pm 0.20 *$ & 0.008 \\
\hline
\end{tabular}

$\mathrm{p}^{* *}$. Level of significance with the Kruskal-Wallis test $\mathrm{p}<0.05, * \mathrm{p}<0.05$ : Compared to Group C $+\mathrm{p}<0.05$ : Compared to Group $\mathrm{S}$

Tab. 2. Hippocampus GFAP data of rats (Mean \pm SD).

\begin{tabular}{cccccc}
\hline & $\begin{array}{c}\text { Group C } \\
(\mathrm{n}=6)\end{array}$ & $\begin{array}{c}\text { Group S } \\
(\mathrm{n}=6)\end{array}$ & $\begin{array}{c}\text { Group A } \\
(\mathrm{n}=6)\end{array}$ & $\begin{array}{c}\text { Group AS } \\
(\mathrm{n}=6)\end{array}$ & $\mathrm{p}^{* *}$ \\
\hline GFAP & $1.00 \pm 0.00$ & $1.00 \pm 0.00$ & $1.67 \pm 0.52^{*,+}$ & $2.00 \pm 0.00^{*,+}$ & $<0.0001$ \\
\hline
\end{tabular}

$\mathrm{p}^{* *}:$ Level of significance with the Kruskal-Wallis test $\mathrm{p}<0.05,{ }^{*} \mathrm{p}<0.05$ : Compared to Group $\mathrm{C}^{+} \mathrm{p}<0.05$ : Compared to Group $\mathrm{S}$

Tab. 3. Brain tissue caspase 3 activity data of rats.

\begin{tabular}{lcccc}
\hline Rat & $\begin{array}{c}\text { Group C } \\
(\mathrm{n}=6)\end{array}$ & $\begin{array}{c}\text { Group S } \\
(\mathrm{n}=6)\end{array}$ & $\begin{array}{c}\text { Group A } \\
(\mathrm{n}=6)\end{array}$ & $\begin{array}{c}\text { Group AS } \\
(\mathrm{n}=6)\end{array}$ \\
\hline 1 & Less than 1\% & Less than 1\% & Less than 1\% & Less than 1\% \\
2 & Less than 1\% & Less than 1\% & $2 \%$ & Less than $1 \%$ \\
3 & Less than 1\% & Less than 1\% & Less than 1\% & $3 \%$ \\
4 & Less than 1\% & $2 \%$ & $1 \%$ & $1 \%$ \\
5 & Less than 1\% & Less than 1\% & $1 \%$ & $3 \%$ \\
6 & Less than 1\% & Less than 1\% & Less than 1\% & Less than 1\% \\
\hline
\end{tabular}

\section{Biochemistry}

Fasting blood samples were obtained to plain tubes. Sera were separated after centrifugation at $1600 \mathrm{~g}$ for 10 minutes and stored at $-80{ }^{\circ} \mathrm{C}$ until the analyzing time.

\section{Thiol-disulfides homeostasis parameters measurement}

Thiol/Disulfide Homeostasis tests were evaluated by automated spectrophotometric method described by Erel \& Neselioglu. For short, disulfide bonds were first reduced to form free functional thiol groups with sodium borohydride. Unused reductant sodium borohydride was consumed and removed with formaldehyde to prevent reduction of DTNB (5,5'-dithiobis-(2-nitrobenzoic) acid), and all of the thiol groups including reduced and native thiol groups were determined after the reaction with DTNB. Half of the difference between the total thiols and native thiols provided the dynamic disulfide amount. After the determination of native and total thiols, disulphide amounts, disulphide/total thiol percent ratios (SS/ $\mathrm{SH}+\mathrm{SS})$, disulfide/native thiol percent ratios $(\mathrm{SS} / \mathrm{SH})$ and native thiol/total thiol percent $\operatorname{ratios}(\mathrm{SH} / \mathrm{SH}+\mathrm{SS})$ were calculated (20).

\section{Catalase activity assay}

Catalase (CAT) activity was measured by Goth's method (21). Sample $(0.2 \mathrm{ml})$ was incubated in $1.0 \mathrm{ml}$ substrate $(65 \mu \mathrm{mol}$ per $\mathrm{H}_{2} \mathrm{O}_{2}$ in $60 \mathrm{mmol} / \mathrm{L}$ sodium-potassium phosphate buffer, $\mathrm{pH}$ 7.4 ) at $37^{\circ} \mathrm{C}$ for 60 seconds. The enzymatic reaction was stopped with $1.0 \mathrm{ml}$ of $32.4 \mathrm{mM}$ ammonium molybdate, and the yellow complex of molybdateand $\mathrm{H}_{2} \mathrm{O}_{2}$ was measured at $405 \mathrm{~nm}$ against a blank. One unit of CAT decomposes $1 \mu \mathrm{mol}$ of $\mathrm{H}_{2} \mathrm{O}_{2} \mathrm{~min}^{-1}$ under these conditions. Results were expressed as $\mathrm{kU} / \mathrm{L}$, which was calculated as followed:

Serum catalase activity $(\mathrm{KU} / \mathrm{l})=(\mathrm{A}($ blank 2$)-\mathrm{A}($ blank 3$) /$ A (sample) - A (blank 1)) $\times 271$

Blank 1 contained $1.0 \mathrm{ml}$ substrate, $1.0 \mathrm{ml}$ molybdate, and $0.2 \mathrm{ml}$ of sample.

Blank 2 contained $1.0 \mathrm{ml}$ substrate, $1.0 \mathrm{ml}$ molybdate and $0.2 \mathrm{ml}$ buffer.

Blank 3 contained $1.0 \mathrm{ml}$ buffer, $1.0 \mathrm{ml}$ molybdate and 0.2 $\mathrm{ml}$ buffer (21).

Tab. 4. Serum catalase, myeloperoxidase, ferroxidase data of rats (Mean \pm SD).

\begin{tabular}{|c|c|c|c|c|c|}
\hline & $\begin{array}{c}\text { Group C } \\
(n=6)\end{array}$ & $\begin{array}{c}\text { Group S } \\
(n=6)\end{array}$ & $\begin{array}{c}\text { Group A } \\
(n=6)\end{array}$ & $\begin{array}{c}\text { Group AS } \\
(\mathrm{n}=6)\end{array}$ & $\mathrm{p}^{* *}$ \\
\hline Catalase(IU/ g protein) & $9.30 \pm 4.74$ & $11.77 \pm 4.15$ & $30.42 \pm 8.70^{*,+}$ & $33.34 \pm 14.32^{*,+}$ & $<0.0001$ \\
\hline Myeloperoxidase(IU/g protein) & $127.66 \pm 12.17$ & $140.33 \pm 8.66$ & $163.23 \pm 16.61^{*,+}$ & $187.82 \pm 24.43^{*,+\&}$ & $<0.0001$ \\
\hline Ferroxidase(IU/g protein) & $27.70 \pm 5.38$ & $31.66 \pm 2.62$ & $36.87 \pm 7.03^{*}$ & $39.72 \pm 6.19^{*}$ & 0.042 \\
\hline
\end{tabular}

$\mathrm{p}^{* * *}$ : Level of significance with the Kruskal-Wallis test $\mathrm{p}<0.05,{ }^{*} \mathrm{p}<0.05$ : Compared to Group $\mathrm{C},{ }^{+} \mathrm{p}<0.05$ : Compared to Group $\mathrm{S},{ }^{\&} \mathrm{p}<0.05$ : Compared to Group A

Tab. 5. Serum thiol data of rats (Mean \pm SD).

\begin{tabular}{|c|c|c|c|c|c|}
\hline & $\begin{array}{c}\text { Group C } \\
(n=6)\end{array}$ & $\begin{array}{c}\text { Group S } \\
(n=6)\end{array}$ & $\begin{array}{c}\text { Group A } \\
(n=6)\end{array}$ & $\begin{array}{c}\text { Group AS } \\
(n=6)\end{array}$ & $\mathrm{p}^{* *}$ \\
\hline Native thiol (Umol/g protein) & $35.95 \pm 3.38$ & $32.88 \pm 3.32$ & $29.75 \pm 3.33^{*}$ & $25.75 \pm 4.00^{*,+}$ & $<0.0001$ \\
\hline Total thiol (Umol/g protein) & $79.16 \pm 7.88$ & $78.09 \pm 7.56$ & $65.24 \pm 10.96^{*,+}$ & $64.88 \pm 7.94^{*,+}$ & 0.010 \\
\hline Disulfide (Umol/g protein) & $15.68 \pm 4.12$ & $18.27 \pm 3.53$ & $23.38 \pm 4.54^{*}$ & $25.35 \pm 4.48^{*,+}$ & 0.003 \\
\hline
\end{tabular}

$\mathrm{p}^{* *}$ : Level of significance with the Kruskal-Wallis test $\mathrm{p}<0.05,{ }^{*} \mathrm{p}<0.05$ : Compared to Group $\mathrm{C}^{+} \mathrm{p}<0.05$ : Compared to Group $\mathrm{S}$ 


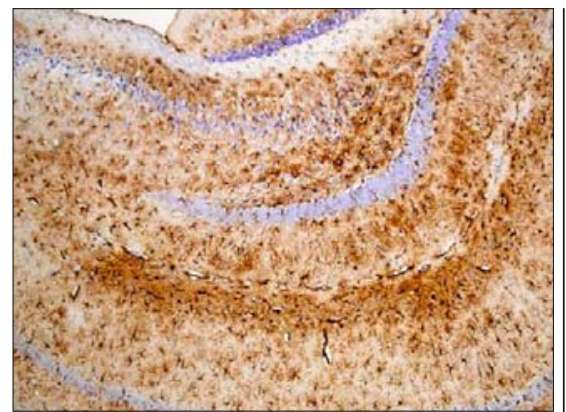

Fig. 3. GFAP (X100) in hippocampus tissues of rats in control group.

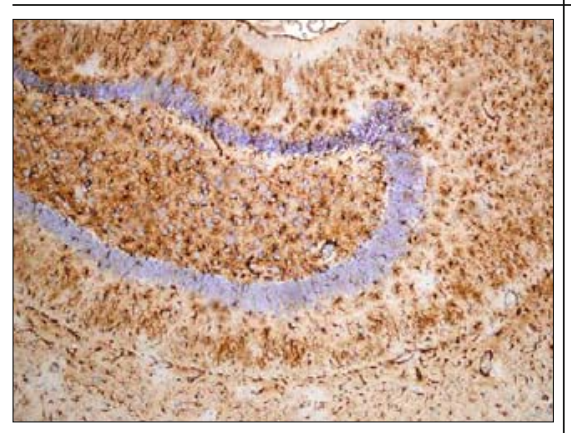

Fig. 5. GFAP (x 400) in hippocampus tissues of rats in Alzheimer's group.

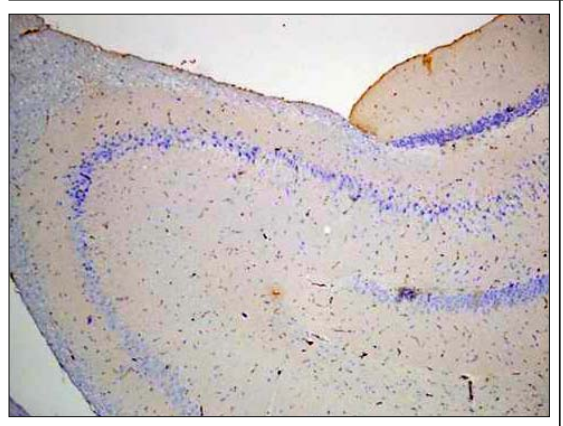

Fig. 7. Caspase 3 (X 100) in the brain tissue of rats in control group.

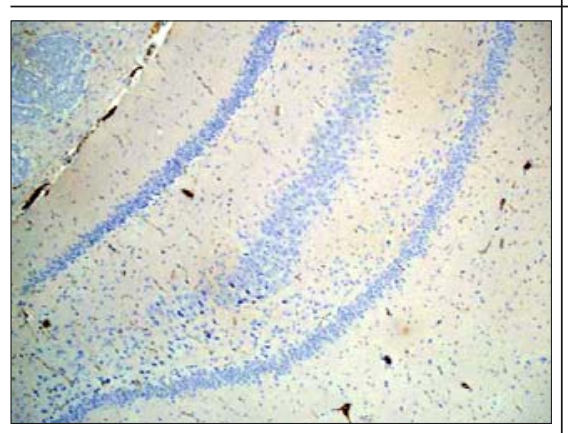

Fig. 9. Caspase 3 (X 100) in the brain tissue of rats in Alzheimer's group.

\section{Measurements of myeloperoxidase}

Serum MPO activity was measured by a modification of the o-dianisidine method (1) based on kinetic measurement at $460 \mathrm{~nm}$ with the rate of the yellowish orange product formation from the

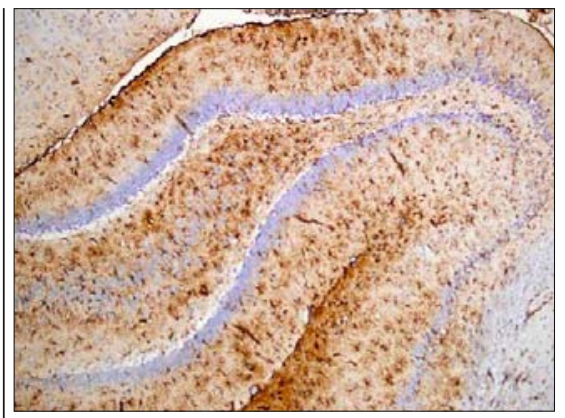

Fig. 4. GFAP $(x 400)$ in hippocampus tissues of rats in sevoflurane group.

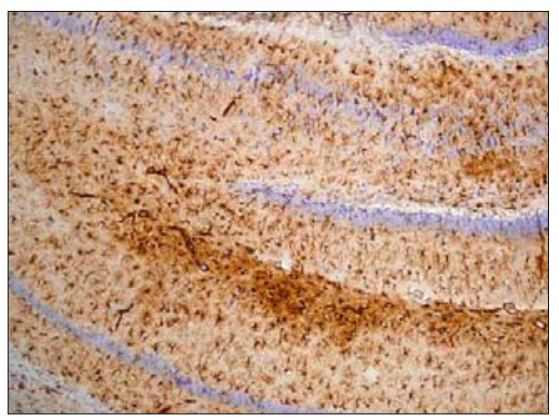

Fig. 6. GFAP (X100) in hippocampus tissues of rats in Alzheimer's-sevoflurane group.

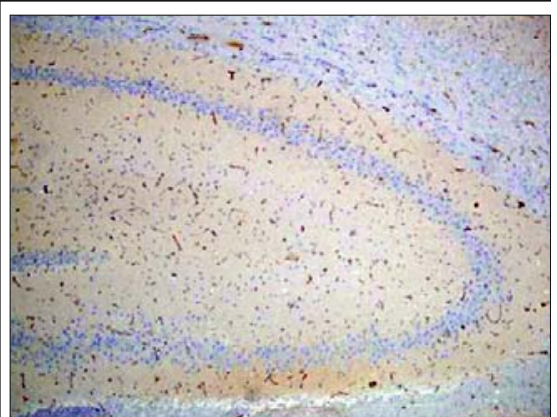

Fig. 8. Caspase 3 (X 100) in the brain tissue of rat in sevoflurane group.

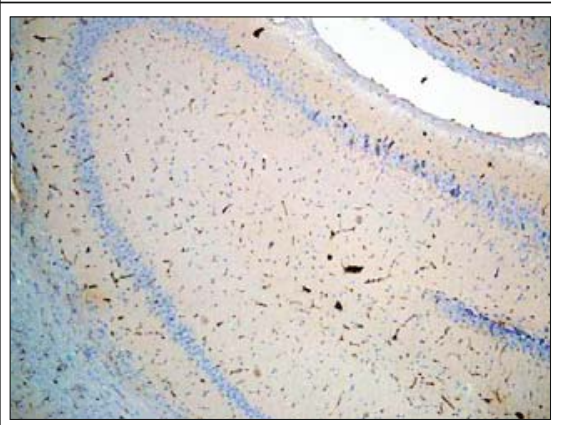

Fig. 10. Caspase 3 (X100) in the brain tissue of rats in Alzheimer-sevoflurane group. oxidation of o-dianisidine with MPO in the presence of hydrogen peroxide $\left(\mathrm{H}_{2} \mathrm{O}_{2}\right)$. One unit of MPO was defined as that degrading $1 \mu \mathrm{mol}$ of $\mathrm{H}_{2} \mathrm{O}_{2} \mathrm{~min}^{-1}$ at $25{ }^{\circ} \mathrm{C}$. A molar extinction coefficient of $1.13 \times 10^{4}$ of oxidized o-dianisidine was used for the calculation. MPO activity was expressed in units per liter serum (22).

\section{Ceruloplasmin measurement}

CLP levels were measured by method described by Erel O (1998). This method is automated, colorimetric and based on the enzymatic oxidation of ferrous ion to ferric ion. The results were expressed in units per liter serum (23).

\section{Statistical analysis}

All the data were processed by variance analysis in The Statistical Package for the Social Sciences (SPSS, Chicago, IL, USA) 20.0 program for Windows statistical software. Kruskal-Wallis test was used to assess the results. Bonferroni adjusted MannWhitney U test was used after significant Kruskal-Wallis to determine, which group differs from the other. The data were expressed as the mean \pm standard error (Mean $\pm \mathrm{SE}$ ). $\mathrm{p}$ value less than 0.05 was considered statistically significant.

\section{Results}

In all the groups, while the number of RAM input-output was similar in the beginning, after Alzheimer's formation, it was significantly decreased in the Group A and the Group AS after 2 weeks. This decrease was significant in all the measurements according to the Group C. In the Group S, after the 2nd. \& 3rd. anesthesia applications, the number of RAM input-output decreased significantly (Tab. 1). Glial fibrillary acidic protein levels in hippocampus tissues of rats were significantly higher in the Group AS compared to $\mathrm{C}$ and $\mathrm{S}$ groups (Tab. 2, Figs 3-6).

The brain tissue caspase 3 activity of the rats was less than $1 \%$ in all rats in the Group C, $3 \%$ in 2 rats and $1 \%$ in 1 rat in the Group AS (Tab. 3, Figs 7-10).

In the Group A and AS, serum catalase, myeloperoxidase and ferroxidase activities were found to be higher than the other groups and myeloperoxidase activity in Group AS was higher than in the Group A (Tab. 4). 
Serum nativethiol, total thiol and disulfide levels were found to be significantly different in Group A and Group AS (Tab. 5).

\section{Discussion}

In our study, we determined that there was an impairment in cognitive functions after repeated sevoflurane anesthesia in rats with STZ induced Alzheimer's disease and we demonstrated this worsening immunohistochemically and pathologically. Callaway et al affirmed that sevoflurane anesthesia did not impair acquisition learning and retention memory 12 weeks later than anesthesia exposure in young adult or aged rats (24). However, $\mathrm{Xu} \mathrm{X}$ et al reported that sevoflurane reduced working memory and functional connectivity between PFC excitatory neurons of aged rats at day 1 after exposure, but it had no effect in adult rats (25). Furthermore Huang Li et al claimed that hispidulin can offer a protection against sevoflurane-induced neurological dysfunction, hispidulin has the potential to be a neuroprotective agent that can improve the cognitive and memory function of elderly patients undergoing anesthesia (26). The role of anesthesia on cognitive function is still controversial. It is thought that not only anesthetic agents, but also neurotoxicity, inflammation, stress, intraoperative factors (e.g. hypotension, hypoglycemia) or the type of surgery have a role in the development of POCD $(1,27)$. However, in recent researches there was an increasing concern that volatile anesthetics may impair cognitive functions over a long period of time, especially in older patients. Research showed that volatile anesthetics could increase amyloid peptide $(\mathrm{A} \beta$ ) production and neurotoxicity, which are important pathological changes in $\mathrm{AD}$ development $(1,11,12)$. Therefore, anesthesia and surgery are assumed as the risk factors that accelerate the onset of $\mathrm{AD}$. Although many reports indicated that there was a relationship between cognitive dysfunction and anesthesia in patients with Alzheimer's disease, there are many researches showing the opposite (28-30). Bohem et al evaluated the patients, who were followed-up between 1974-1984 years and who had been anesthetized at least once before developing Alzheimer's disease. Overall, they point out that a multiple exposure to general anesthesia had no effect on AD development (28). There was no correlation between the risk of general anesthesia exposure and the development of $\mathrm{AD}$ in systemic review and metaanalysis by Seitz et al (30). Tian Y et al demonstrated that sevoflurane exacerbates cognitive impairment induced by $A \beta 1-40$ in rats by initiating neurotoxicity, neuroinflammation, and neuronal apoptosis in rat hippocampus (31). However, this is the first study to demonstrate the immunohistochemical and biochemical change after recurrent sevoflurane anesthesia in rat with Alzheimer disease. In our study, we performed a RAMT to evaluate the cognitive functions after creating Alzheimer model with STZ induced and repeated sevoflurane anesthesia. The RAMT was designed by Olton \& Samuelson. Radial Arm Maze Test has been commonly used by researchers for measuring spatial learning and memory in rodents; it allows for the evaluation of spatial working and reference memory (18). In the RAM test, we observed the number of input-output on the arms. There was no difference between the rats before the sevoflurane exposure. There was a significant dif- ference between the rats when the RAM test was applied after a repeated sevoflurane anesthesia.

Potential mechanisms for either postoperative cognitive disorder or neurodegeneration are numerous, ranging from N-methyl-Daspartate-mediated excitotoxicity to oxidant stress or suppression of cholinergic signaling. Eckenhoff et al in vivo demonstrated that inhaled anesthetics led to an increase of toxic forms of amyloid- $\beta$ (11). In their study, Verkhratsky et al noted that GFAP labeling changed between brain regions, when the brain tissues of Alzheimer's patients are examined. GFAP was positive in $80 \%$ astrocytes in the hippocampal tissue $(32,33)$. In our experiment, when the rat's hippocampus was evaluated histopathologically, GFAP was present more in the Alzheimer + sevo Group compared to the Control Group and the Alzheimer Group.

Antioxidants are substances that can clean free radicals and prevent cell damage. Myeloperoxidase is an intracellular antioxidant enzyme stored in neutrophil granules. An increase in the production of free radicals or reduction of these antioxidant systems will cause an oxidative stress. Oxidative stress has been found to be related to numerous disorders including infection, diabetes, cancer, neurodegenerative and cardiovascular diseases $(34,35)$ In $\mathrm{AD}$, several experimental and clinical researches determinate that oxidative damage plays the pivotal role in neuron loss and progression to dementia (36).

Yong Qiao et.all showed that in patients receiving sevoflorane anesthesia (90 patients 65-75 years old), POCD was more frequent and these patients had a higher plasma IL- 6 and TNF- $\alpha$ values (37). In our study, we demonstrated that serum catalase myeloperoxidase activities were higher after a repeated sevoflurane anesthesia.

Caspases are crucial mediators of programmed cell death (apoptosis). Caspase-3 is essential for normal brain development and is important or essential in other apoptotic scenarios in a remarkable tissue-cell type-or death stimulus-specific manner (38). Caspase-3 activation, caspase-3-cleaved-b-actin and caspase-cleaved-APP were found in brains of AD patients. Also, an increasing evidences suggests a role for caspase activation and apoptosis in AD neuropathogenesis (39). In neurodegenerative diseases such as Alzheimer's and Parkinson's it is thought that apoptosis was induced and neurons died in an unexplained manner. Ostapchenko et al demonstrated that Caspase-3 activity was associated with an increased risk of Alzheimer's disease (40). Previous studies demonstrated that sevoflurane and isoflurane induced apoptosis in normal peripheral blood mononuclear cells and Human T Lymphocytes in vitro $(41,42)$. In our study, caspase-3 activity was lower than $1 \%$ in control and in other groups, while in 2 rats in group AS it was more than 3\% than in control groups.

Thioldisulphide homeostasis status has acritical role in antioxidant protection, detoxification, signal transduction, apoptosis, regulation of enzymatic activity and transcription factors and cellular signaling mechanisms (43). Thiols, as is known, are the class of organic compounds containing a sulfhydryl group (-SH) consisting of a hydrogen and a sulfur atom attached to a carbon atom. This $-\mathrm{SH}$ groups react with oxidant molecules to protect the organism from oxidative damage. Thiols are converted to disulfide during this reaction and the amount of thiol decreases. 
These disulfide bonds can be reduced to the thiol group, so that dynamic thiol disulfide homeostasis continues. Thiols contribute to the majority of the total antioxidants in the body and play an important role in body defense (44-47). Recent studies showed that the presence of an abnormal thiol/disulfide homeostasis has a role in the pathogenesis of various acute and chronic diseases (48-50). Oxidative stress, altered GSH levels, hyperhomocysteinemia, vitamin B deficiency and amyloid- $\beta$ levels play critical roles in $\mathrm{AD}$ (51). In our study in the AS group; when compared to the control group, the levels of Nativethiol and total thiol decreased but disulfide levels increased, this was found to be statistically significant.

Finally, the relationship between AD and anesthesia is not well understood. In elderly rats with streptozotocin-induced experimental Alzheimer's disease, it was found that the sevoflurane anesthesia has negatively affected cognitive functions evaluated with RAMT at minimum level, and histopathological and biochemical markers supported these findings. In order to correlate these results with the clinical applications, we think that observational studies should be conducted in large series.

\section{References}

1. Isik B. Postoperative cognitive dysfunction and Alzheimer disease. Turk J Med Sci 2015; 45 (5): 1015-1019.

2. Papon MA, Whittington RA, El-Khoury NB, Planel E. Alzheimer's disease and anesthesia. Front Neurosci 2011; 4: 272.

3. Bufill E, Bartés A, Moral A, Casadevall T, Codinachs M, Zapater E, Carles Rovira J, Roura P, Oliva R, Blesa R. Genetic and environmental factors that may influence in the senile form of Alzheimer's disease: nested case control studies. Neurologia 2009; 24 (2): 108-112.

4. Morris JK, Honea RA, Vidoni ED, Swerdlow RH, Burns JM. Is Alzheimer's disease a systemic disease? Biochim Biophys Acta 2014; 1842: 1340-1349.

5. Moller JT, Cluitmans P, Rasmussen LS, Houx P, Rasmussen H et al. Long-term postoperative cognitive dysfunction in the elderly ISPOCD1 study. ISPOCD investigators. International Study of Post-Operative Cognitive Dysfunction. Lancet 1998; 351: 857-861.

6. Abildstrom H, Rasmussen LS, Rentowl P, Hanning CD, Rasmussen $\mathrm{H}$ et al. Cognitive dysfunction 1-2 years after non-cardiac surgery in the elderly. ISPOCD group. International Study of Post- Operative Cognitive Dysfunction. Acta Anaesthesiol Scand 2000; 44: 1246-1251.

7. Monk TG, Weldon BC, Garvan CW, Dede DE, van der Aa MT, Heilman KM, Gravenstein JS. Predictors of cognitive dysfunction after major noncardiac surgery. Anesthesiology 2008; 108: 18-30.

8. Johnson T, Monk T, Rasmussen LS, Abildstrom H, Houx P et al. Postoperative cognitive dysfunction in middle-aged patients. Anesthesiology 2002; 96: 1351-1357.

9. Ancelin ML, de Roquefeuil G, Ledesert B, Bonnel F, Cheminal JC, Ritchie K. Exposure to anaesthetic agents, cognitive functioning and depressive symptomatology in the elderly. Br J Psychiatry 2001; 178: 360-366.

10. Ikeda Y, Ishiguro K, Fujita SC. Ether stress-induced Alzheimerlike tau phosphorylation in the normal mouse brain. FEBS Lett 2007; 581: 891-897.
11. Eckenhoff RG, Johansson JS, Wei H, Carnini A, Kang B et al. Inhaled anesthetic enhancement of amyloid-beta oligomerization and cytotoxicity. Anesthesiology 2004; 101 (3): 703-709.

12. Xie Z, Culley DJ, Dong Y, Zhang G, Zhang B,Moir RD, Frosch MP, Crosby G, Tanzi RE. The common inhalation anesthetic isoflurane induces caspase activation and increases amyloid beta-protein level. Ann Neurol 2008; 64 (6): 618-627.

13. Mandal PK, Fodale V. Isoflurane and desflurane at clinically relevant concentrations induce amyloid beta-peptide oligomerization: an NMR study. BiochemBiophys Res Commun 2009; 379 (3): 716-720.

14. Run X, Liang Z, Zhang L et al. Anesthesia induces phosphorylation of tau. J Alzheimers Dis 2009; 16 (3): 619-626.

15. Song J, Hur BE, Bokara KK, Yang W, Cho HJ et al. Agmatine Improves Cognitive Dysfunction and Prevents Cell Death in a Streptozotocin-Induced Alzheimer Rat Model. Yonsei Med J 2014; 55 (3): 689-699.

16. Xu ZP, Li L, Bao J, Wang ZH, Zeng J et al. Magnesium Protects Cognitive Functions and Synaptic Plasticity in Streptozotocin-Induced Sporadic Alzheimer's Model. PLoS One 2014; 9 (9): e108645.

17. Chen D. Neuroprotective effect of amorphophallus campanulatus in stz induced alzheimer rat model. Afr J Tradit Complement Altern Med 2016; 3; 13 (4): 47-54.

18. Kim H, Park JY, Kim KK. Spatial Learning and Memory Using a Radial Arm Maze with a Head-Mounted Display. Psychiatry Investig 2018; 15 (10): 935-944.

19. Mizuno M, Yamada K, Olariu A, Nawa H, Nabeshima T. Involvement of brain-derived neurotrophic factor in spatial memory formation and maintenance in a radial arm maze test in rats. J Neurosci 2000; 20 : 7116-7121.

20. Erel O, Neselioglu S. A novel and automated assay for thiol/disulfide homeostasis. Clin Biochem. DOI: 10.1016/j.clinbiochem.2014.09.026.

21. Goth L. A simple method for determination of serum catalase activity and revision of reference range. Clin Chim Acta 1991; 196: 143-152.

22. Bradley PP, Priebat DA, Christensen RD, Rothstein G. Measurement of cutaneous inflammation: estimation of neutrophil content with an enzyme marker. J Invest Dermatol 1982; 78: 206-209.

23. Erel O. Automated measurement of serum ferroxidase activity. Clin Chem 1998; 4: 313-319

24. Callaway JK, Jones NC, Royse AG, Royse CF. Sevoflurane anesthesia does not impair acquisition learning or memory in the Morris water maze in young adult and aged rats. Anesthesiology 2012; 117 (5): 1091-1101.

25. Xu X, Tian X, Wang G. Sevoflurane reduced functional connectivity of excitatory neurons in prefrontal cortex during working memory performance of aged rats. Biomed Pharmacother 2018; 106: 1258-1266.

26. Huang L, Huang K, Ning H. Hispidulin prevents sevoflurane- Induced memory dysfunction in aged rats. Biomed Pharmacother 2018; 97: 412-422.

27. Palotás A, Reis HJ, Bogáts G, Babik B, Racsmány M, Engvau L, Kecskeméti E, Juhász A, Vieira LB, Teixeira AL et al. Coronary artery bypass surgery provokes Alzheimer's disease-like changes in the cerebrospinal fluid. J Alzheimers Dis 2010; 21: 1153-1164.

28. Bohnen NI, Warner MA, Kokmen E, Beard CM, Kurland LT. Alzheimer's disease and cumulative exposure to anesthesia: a case-control study. J Am Geriatr Soc 1994; 42: 198-201. 
29. Zuo C, Zuo Z. Spine surgery under general anesthesia may not increase the risk of Alzheimer's disease. Dement Geriatr Cogn Disord 2010; 29: 233-239.

30. Seitz DP, Shah PS, Herrmann N, Beyene J, Siddiqui N. Exposure to general anesthesia and risk of Alzheimer's disease: a systematic review and meta-analysis. BMC Geriatr 2011; 11: 83.

31. Tian Y, Chen KY, Liu LD, Dong YX, Zhao P, Guo SB. Sevoflurane Exacerbates Cognitive Impairment Induced by A $\beta(1-40)$ in Rats through Initiating Neurotoxicity, Neuroinflammation, and Neuronal Apoptosis in Rat Hippocampus. Mediators Inflamm 2018; 2018: 3802324.

32. Verkhratsky A, Olabarria M, Noristani HN, Yeh CY, Rodriguez JJ. Astrocytes in Alzheimer's Disease. Neurotherapeutics 2010; 7 (4): 399-412.

33. Kimelberg HK. The problem of astrocyte identity. Neurochem Int 2004; 45: 191-202.

34. Christen Y. Oxidative stress and Alzheimer disease. Amer J Clin Nutrit 2000; 71: 621S-629S.

35. Singh RP., Sharad S, Kapur S. Free radicals and oxidative stress in neurodegenerative diseases: relevance of dietary antioxidants. Journal, Indian Academy of Clinical Medicine 2004; 5: 218-225.

36. Pizzino G, Irrera N, Cucinotta M, Pallio G, Mannino F, Arcoraci V, Squadrito F, Altavilla D, Bitto A. Oxidative Stress: Harms and Benefits for Human Health. Oxid Med Cell Longev 2017; 2017: 8416763.

37. Yong Qiao, Hao Feng, Tao Zhao, Heng Yan, He Zhang, Xin Zhao. Postoperative cognitive dysfunction after inhalational anesthesia in elderly patients undergoing major surgery: the influence of anesthetic technique, cerebral injury and systemic inflammation. BMC Anesthesiol 2015; 15: 154.

38. Porter AG, Jänicke RU. Emerging roles of caspase-3 in apoptosis. Cell Death Differ 1999; 6 (2): 99-104.

39. Xie Z, Tanzi RE. Alzheimer's disease and post-operative cognitive dysfunction. ExpGerontol 2006; 41 (4): 346-359.

40. Ostapchenko VG, Snir J, Suchy M, Fan J, Cobb MR, Chronik BA, Kovacs M, Prado VF, Hudson RHE, Pasternak SH, Prado MAM, Bartha R. Detection of Active Caspase-3 in Mouse Models of Stroke and Alzheimer's Disease with a Novel Dual Positron Emission Tomography/Fluorescent Tracer [68Ga]Ga-TC3-OGDOTA Contrast Media Mol Imaging 2019; 2019: 6403274.
41. Loop T, Dovi-Akue D, Frick M et al. Volatile anesthetics induce caspase-dependent, mitochondria-mediated apoptosis in human T lymphocytes in vitro. Anesthesiology 2005; 102 (6): 1147-1157.

42. Matsuoka H, Kurosawa S, Horinouchi T, Kato M, Hashimoto Y. Inhalation anesthetics induce apoptosis in normal peripheral lymphocytes in vitro. Anesthesiology 2001; 95: 1467-1472.

43. Erel O, Neselioglu S. A novel and automated assay for thiol/disulphide homeostasis. Clin Biochem 2014; 47 (18): 326-332.

44. Sen CK, Packer L. Thiol homeostasis and supplements in physical exercise. Am J Clin Nutr 2000; 72: 653-669.

45. Turell L, Radi R, Alvarez B. Thethiol pool in human plasma: the central contribution of albumin to redox processes. Free Radic Biol Med 2013: 65: 244-253.

46. Jones DP, Liang Y. Measuring the poise of thiol/disulfide couples in vivo. Free Radic Biol Med 2009; 47: 1329-1338.

47. Chianeh YR, Prabhu K. Protein thiols as an indicator of oxidative stress. Arch Med Rev J 2014; 23: 443-456.

48. Ates I, Kaplan M, Yuksel M, Mese D, Alisik M, Erel Ö, Yilmaz N, Guler S. Determination of thiol/disulphide homeostasis in type 1 diabetes mellitus and the factors associated with thiol oxidation. Endocrine 2016; 51 (1): 47-51.

49. Cakici EK, Eroğlu FK, Yazilitas F, Bülbül M, Gür G et al. Evaluation of the level of dynamic thiol/disulphidehomeostasis in adolescent patients with newly diagnosed primary hypertension. Pediatr Nephrol 2018; 33 (5): 847-853.

50. Sivri S, Kasapkara HA, Polat M, Alsancak Y, Durmaz T et al. Dynamic thiol/disulphide homeostasis and its prognostic value in patients with non-ST elevation-acute coronary syndromes. Kardiol Pol 2018; 76 (2): 426-432.

51. Persichilli S, Gervasoni J, Di Napoli A, Fuso A, Nicolia V et al. Plasma thiols levels in Alzheimer's disease mice under diet-induced hyperhomocysteinemia: effect of S-adenosylmethionine and superoxide-dismutase supplementation. J Alzheimers Dis 2015; 44 (4): 1323-1331.

Received May 5, 2019. Acepted June 27, 2019. 